WSRC-RP-91-311-3

\title{
TREND ANALYSIS REPORT (U): REACTOR RESTART DIVISION SECOND QUARTER 1991
}

by

Westinghouse Savannah River Company

WSRC-RP- $-91-311-3$

Savannah River Site

DE93 005513

Aiken, South Carolina 29808

Other Authors:

This paper was prepared in connection with work done under Contract No. DE-AC09-89SR18035 with the U. S. Department of Energy. By acceptance of this paper, the publisher and/or recipient acknowledges the U. S. Government's right to retain a nonexclusive, royalty-free license in and to any copyright covering this paper, along with the right to reproduce and to authorize others to reproduce all or part of the copyrighted paper.

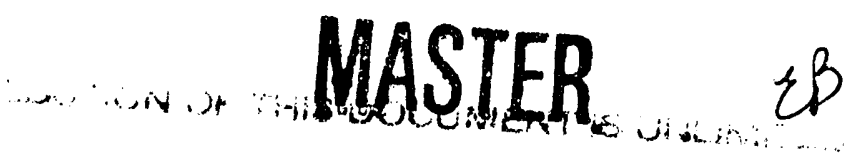




\section{DISCLAIMER}

This report was prepared as an account of work sponsored by an agency of the United States Government. Neither the United States Government nor any agency thereof, nor any of their employees, makes any warranty, express or implied, or assumes any legal liability or responsibility for the accuracy, completeness, or usefuiness of any information, apparatus, product, or process disclosed, or represents that its use would not infringe privately owned rights. Reference herein to any specific commercial product, process, or service by trade name, trademark, manufacturer, or otherwise does not necessarily constitute or imply its endorsement, recommendation, or favoring by the United States Government or any agency thereof. The views and opinions of authors expressed herein do not necessarily state or reflect those of the United States Government or any agency thereof.

This report has been reproduced directly from the best available copy.

Available to DOE and DOE contractors from the Office of Scientific and Technical Information, P.O. Box 62, Oak Ridge, TN 37831; prices available from (615) 576-8401, FTS 626-8401.

Available to the public from the National Technical Information Service, U.S. Department of Commerce, 5285 Port Royal Rd, Springfield, VA 22161. 
TREND ANALYSIS REPORT (U)

Reactor Restart Division

Second Quarter 1991

\section{UNCLASSIFIED}

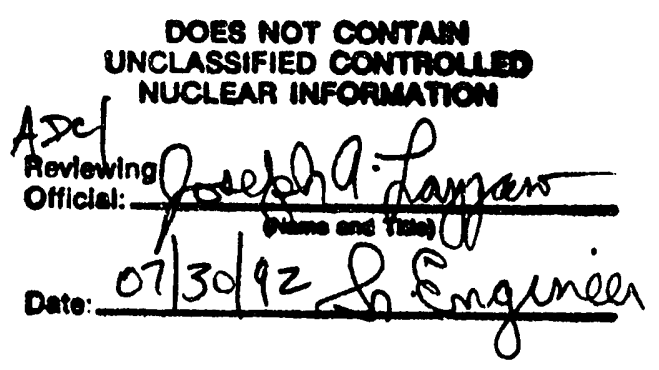

Westinghouse Savannah River Company Savannah River Site Aiken, SC 29808 
WSRC-RP-91-311-3

TREND ANALYSIS REPORT (U)

Reactor Restart Division

Second Quarter 1991

R. B. Castles

Publication Date: October 7, 1991

Westinghouse Savannah River Company

Savannah River Site

Aiken, SC 29808 


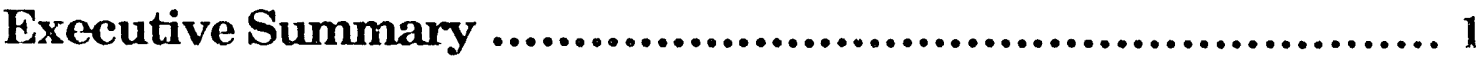

Nonconformance Reports by Area ...................................... 3

Nonconformance Reports by Problem ............................. 4

Nonconformance Report Causal Factors .......................... 6

Nonconformance Report Dispositions ............................. 8

Nonconformance Report Recurrence Prevention.................. 10

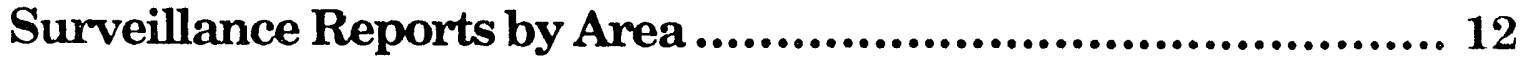

Surveillance Findings................................................. 13

Surveillance Causal Factors .............................................. 15

Surveillance Recurrence Prevention.................................. 17

Corrective Action Reports............................................ 18 


\section{Reactor Restart Division Trend Analysis Report Second Quarter 1991}

Executive Summary

The data contained in this report is comprised of Nonconformance Report (NCR), Surveillance Reports, and Corrective Action Reports (CAR). The data population for this report consisted of 277 data records from the following breakdown:

$\begin{array}{lr}\text { Nonconformance Reports } & 227 \\ \text { Surveillances } & 45 \\ \text { Corrective Action Reports } & 5\end{array}$

The data trended now includes six quarters and provides the capability of looking at changing patterns in the various performance categories over time. Data pertaining to this quarter is displayed in table form for each subject to summarize current performance. In previous reports, area charts have been utilized to evaluate each element's contribution to the combined totals. Beginning with this report, the area charts are replaced with line charts. These charts are shown in two formats, actual and normalized data. The actual chart references each individual contribution without considering variation in the size of the analyzed population. The normalized chart shows the same individual contribution, however variation in population size is factored into the analysis. This allows the standardization of charts and allows the addition of quantifiable goals/limits to be established for each category.

As in the past the basis for determining the elements used in these charts was Pareto analysis of each quarter's data. The data from this individual analysis was then combined and a Pareto analysis was performed to determine major categories for the six reporting periods.

Positive indications include:

- A continued reduction in the overall number of deficiencies. Deficiencies peaked during the Third Quarter 1990 when 800 data records were added. This is the third consecutive quarter for this positive downward trend in total deficiencies.

- A continued downward trend in causal factors reported as "Indeterminate". This positive trend is due to an increased effort by the field to determine an initial probable cause for the deficiency when reported. This eliminates the need to make a subjective call as to causal factors during the trend analysis. 


\section{Reactor Restart Division \\ Trend Analysis Report Second Quarter 1991}

\section{Executive Summary (continued)}

- The Fourth Quarter 1990 report noted the beginning of a decreasing trend for the causal category of Standards, Policies, Administrative Controls (SPAC) Less 'Than Adequate. This category has dropped significantly in overall contribution. However, it continues to be the major contributing causal factor for Surveillance data. While this is noted as an overall positive trend, more investigation is needed with the Surveillance data and this concern will be forwarded to the Surveillance group for further investigation.

One adverse trend requiring corrective action is evident from this analysis. During the analysis of surveillance data a rise is noted in the finding related to "Procedure Violations". This is the start of an adverse trend and the need to re-emphasize compliance with procedures is needed. As new and revised procedures come on line it is imperative that timely training is provided and follow up is made to assure personnel understand these changes. This will establish a solid basis for procedural compliance and avert this condition becoming a significant condition adverse to quality.

Several features will be incorporated into the next Trend Analysis Report. Future reports will be published monthly, ownership identified at department level and deficiencies detailed to the system and component level. These changes will allow for a more proactive analysis of deficiency data and provide timely feedback for corrective action. 


\section{Reactor Restart Division \\ Trend Analysis Report Second Quarter 1991}

Nonconformance Reports

The 227 Nonconformance Reports used in this analysis were distributed among the operating areas as follows:

$\begin{array}{lr}\text { K Area } & 140 \\ \text { L Area } & 55 \\ \text { P Area } & 27 \\ \text { All Areas } & 5\end{array}$

(Not Applicable To One Area)

NCR Areas by Quarter

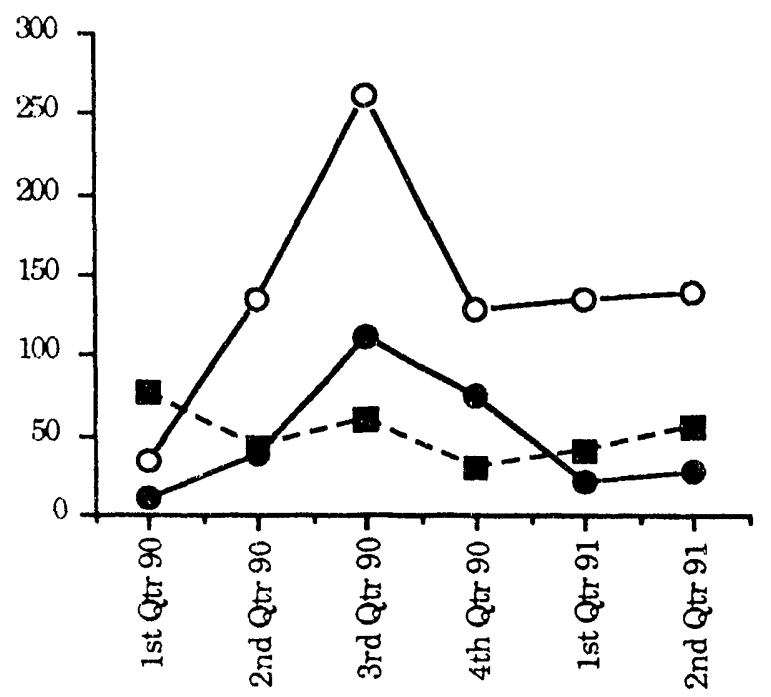

NCR Areas by Quarter (Normalized)

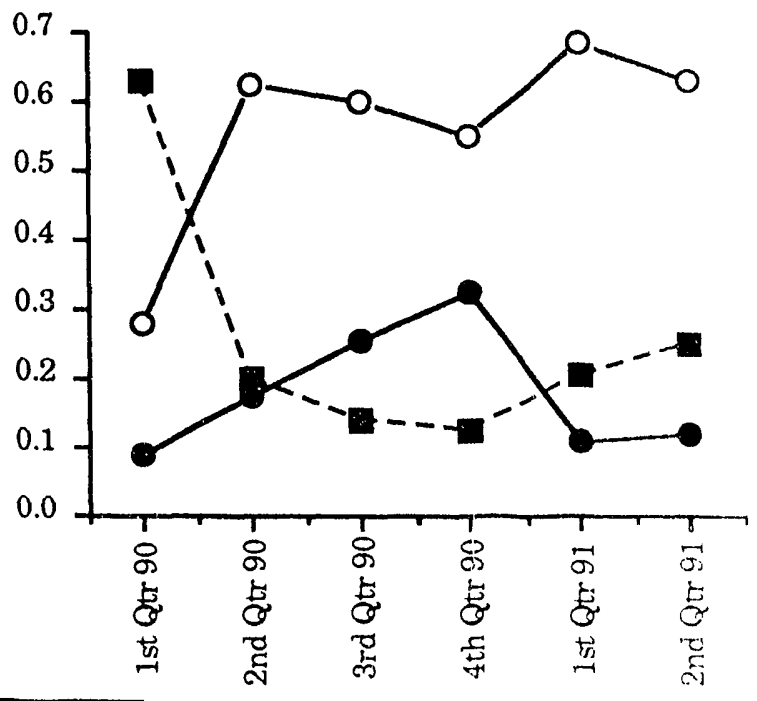

$$
\begin{array}{rr}
-0- & \text { K Area } \\
--6- & \text { L Area } \\
- & \text { P Area }
\end{array}
$$

$\mathrm{K}$ Area continues to dominate in frequency of reports. This dominance is directly attributable to the restart activity in this area. 


\section{Reactor Restart Division \\ Trend Analysis Report Second Quarter 1991}

Problems identified by the NCRs used in this quarter's analysis are:

Installation/Fabrication

Inspection, Test, Surveillance

Calibration Acceptance Failure

Component Failure - Electrical

Component Failure - Mechanical

Leakage

All Others
$1(0)$

50

25

19

5

28
NCR Problem by Quarter (Chart 1)

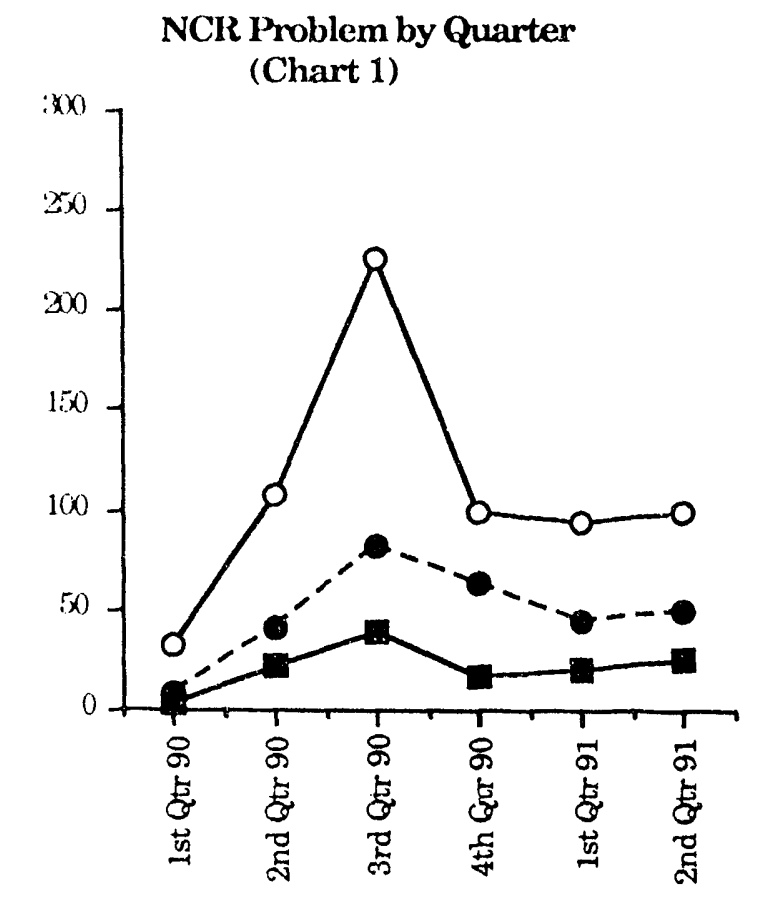

NCR Problem by Quarter (Chart 1 Normalized)

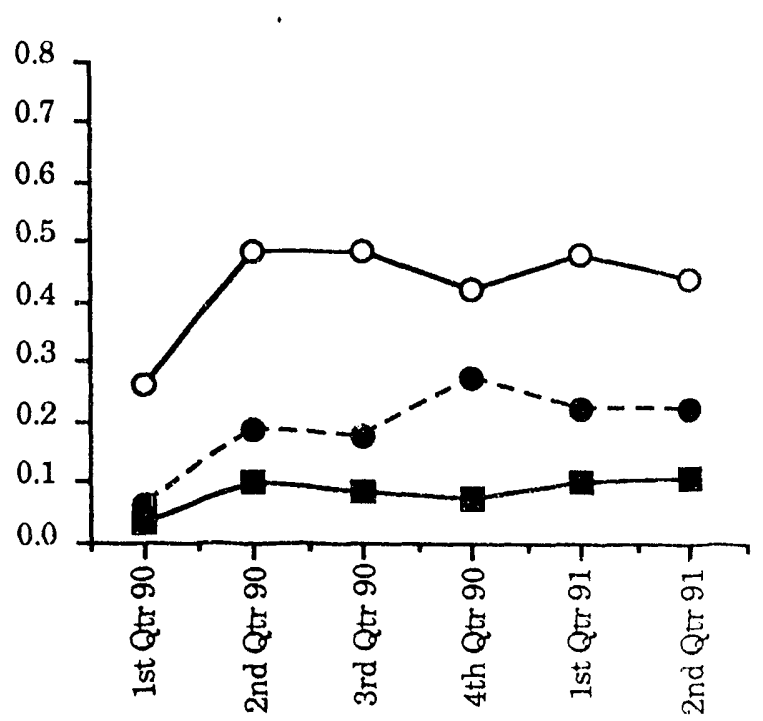

Installation/Fabrication

- - Insp, Test, Surv, Calib Failure

Component Failure - Electrical

No significant changes occurred, the same problems in roughly the same order as the five previous reports are noted this quarter.

"Installation/Fabrication" accounts for forty four percent of the overall deficiencies. The majority of these deficiencies are loose or missing nuts/bolts, mis-landed or mis-connected wires. 


\section{Reactor Restart Division \\ Trend Analysis Report Second Quarter 1991}

(NCR Problem Analysis Continued)

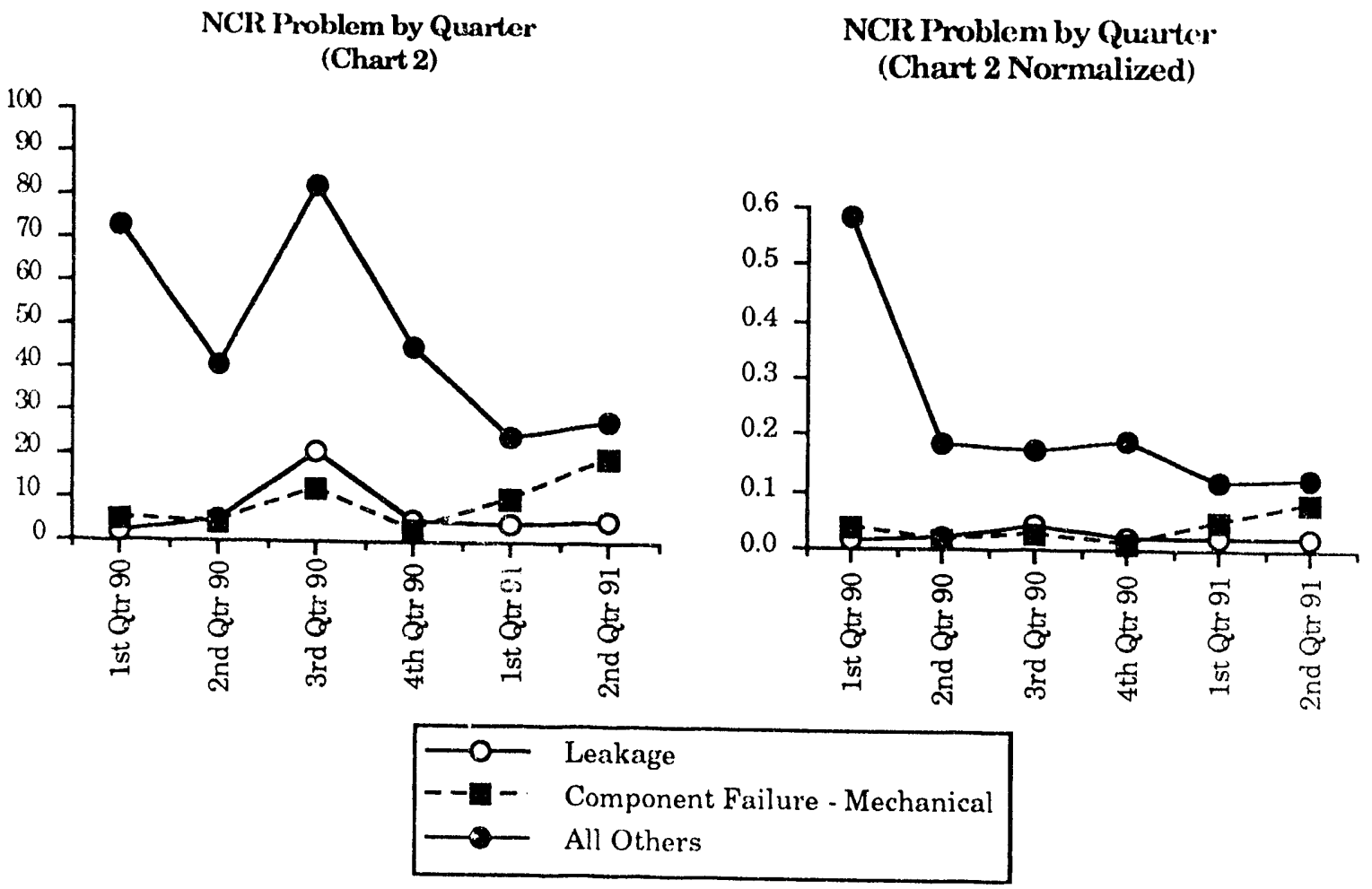

Also rote in Chart 2 the consistent decline in the number of reports grouped in "All Others". This decline is directly attributable to field personnel aiding in the development of clearer more consise problem description categories. 


\section{Reactor Restart Division \\ Trend Analysis Report Second Quarter 1991}

The main causal categories for the identified NCR deficiencies are:

Hardware Failure

Installation Difficulty

Indeterminate

CM/PM Difficulty

Standards, Policies,

Administrative Controls (SPAC) LTA

All Others
61

42

40

40

18

26

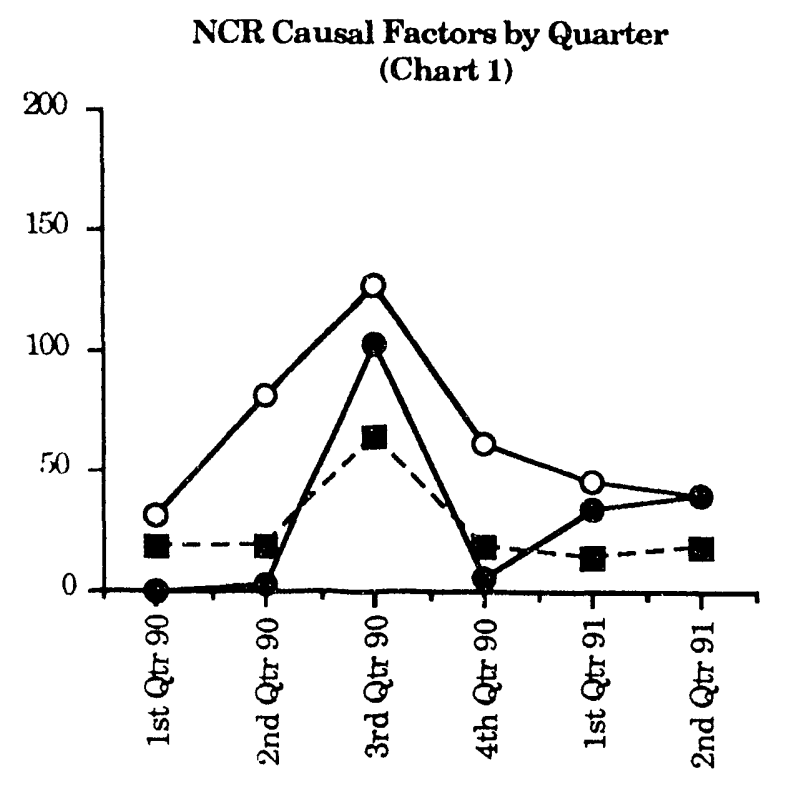

NCR Causal Factors by Quarter (Chart 1 Normalizod)

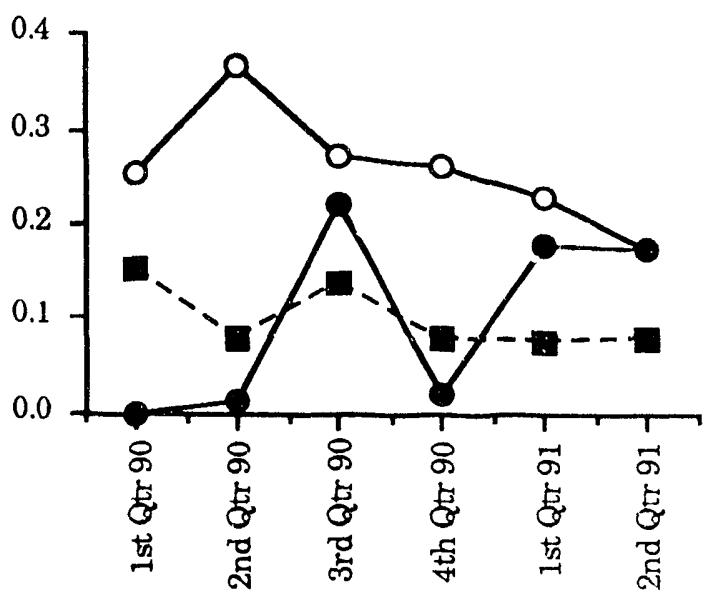

$$
\begin{array}{ll}
-0- & \text { Indeterminate } \\
-- & \text { SPAC LTA } \\
- & \text { CM/PM Difficulty }
\end{array}
$$

It has been noted in two previous reports that "SPAC LTA" continues to decline in its overall contribution to the analysis. This was noted earlier in the report that this category is dropping from significance in relation to NCRs and will be discussed further in the analysis of Surveillances.

There is also a significant reduction in the number of reports that have been categorized as "Indeterminate". This reduction is due to field personnel identifying probable cause for the individual reports. This effort has greatly improved the ability to more easily analyze the individual reports. 


\section{Reactor Restart Division \\ Trend Analysis Report \\ Second Quarter 1991}

(NCR Causal Factor Analysis Continued)

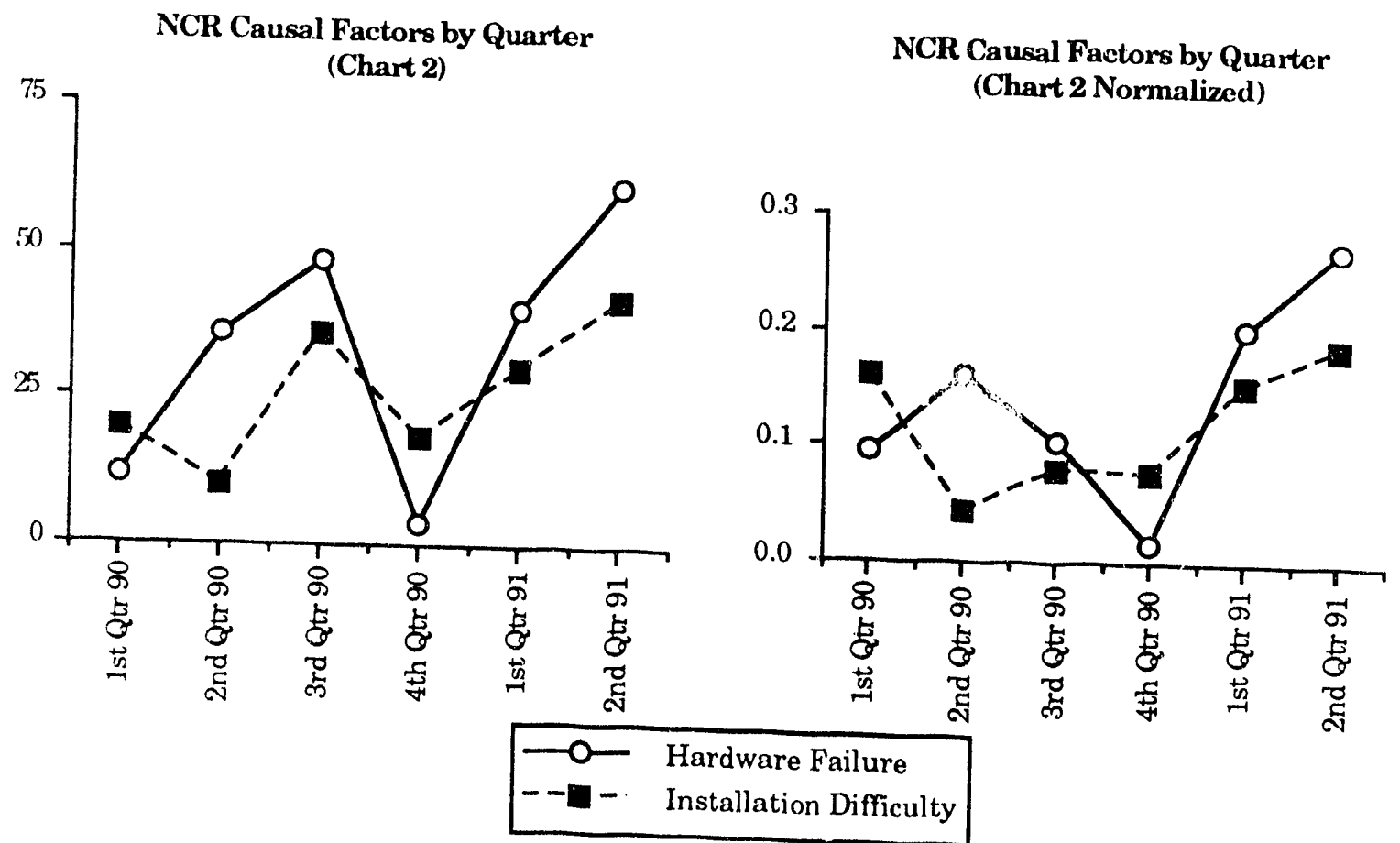

The rise in "Hardware Failures" is directly attributable to the Startup

Testing program currently in progress in K Area. 


\section{Reactor Restart Division \\ Trend Analysis Report \\ Second Quarter 1991}

The dispositions prescribed for the NCR deficiencies are:

$\begin{array}{lr}\text { Rework } & 110 \\ \text { Use-As-Is } & 45 \\ \text { Repair } & 39 \\ \text { Reject } & 8 \\ \text { Programmatic } & 5 \\ \text { All Others } & 20\end{array}$

NCR Dispositions by Quarter (Chart 1)

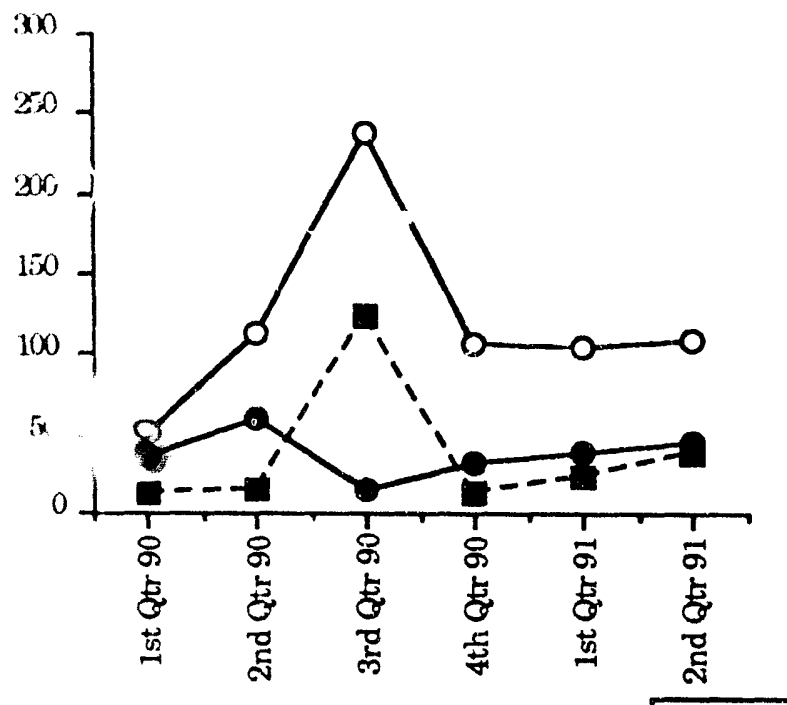

$\begin{array}{cl}-0- & \text { Rework } \\ --1- & \text { Repair } \\ - & \text { Use-As-Is }\end{array}$
NCR Dispositions by Quarter

(Chart 1 Normalized)

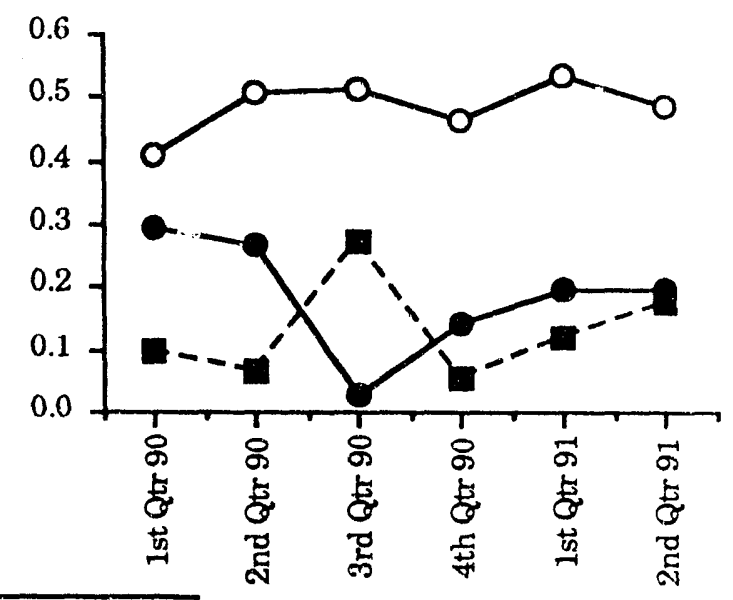

Rework continues to be the most common disposition for NCRs. This is a positive note as systems are being returned to original specifications. 


\section{Reactor Restart Division \\ Trend Analysis Report Second Quarter 1991}

(NCR Disposition Analysis Continued)

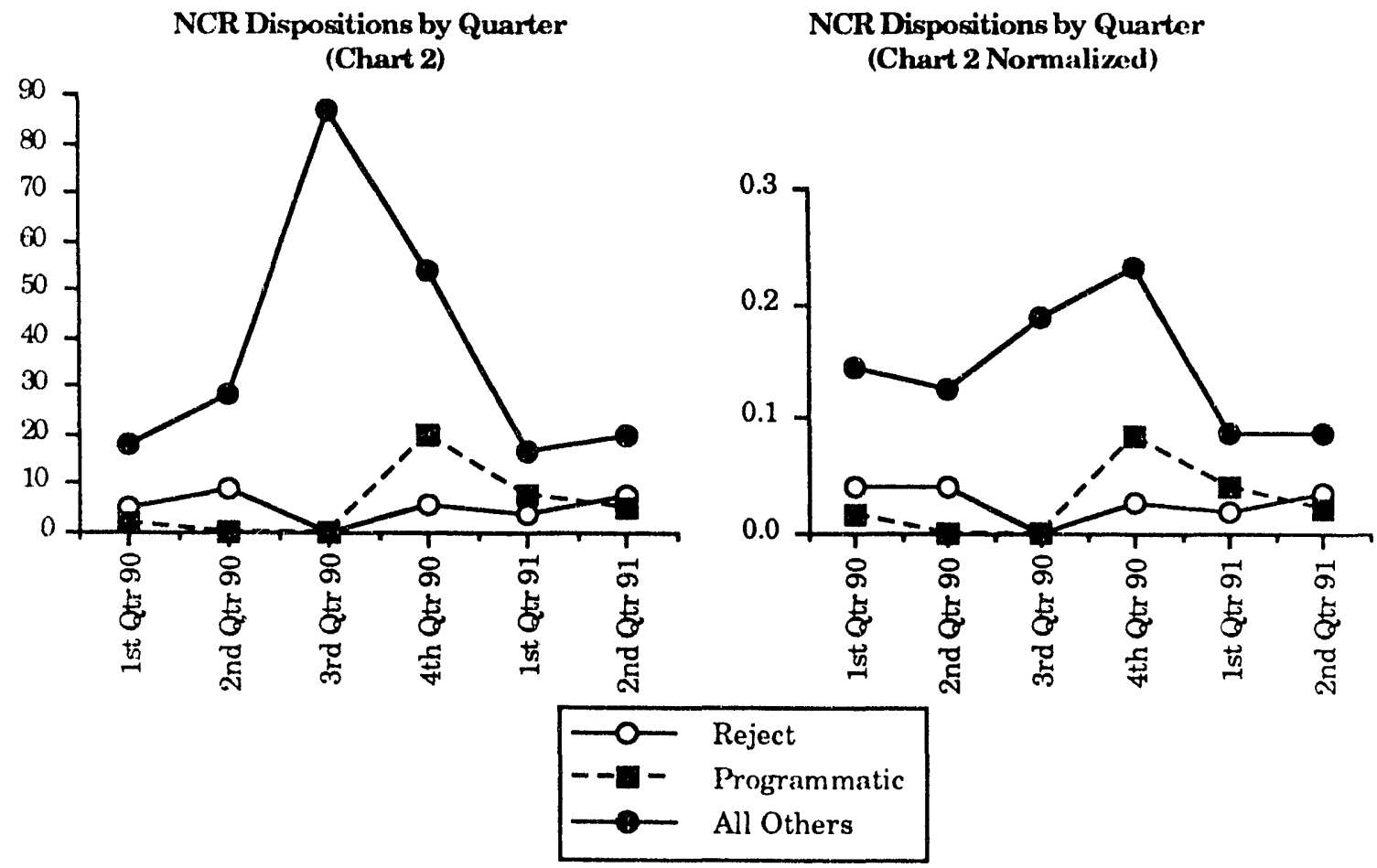




\section{Reactor Restart Division \\ Trend Analysis Report Second Quarter 1991}

Actions To Prevent Recurrence of the NCR noted deficiencies are:

$\begin{array}{lr}\text { Modify Design } & 41 \\ \text { None Noted } & 36 \\ \text { Develop/Revise } & 33 \\ \text { Modify Installation } & 25 \\ \text { Modify CM/PM } & 20 \\ \text { Train } & 6 \\ \text { All Others } & 66\end{array}$

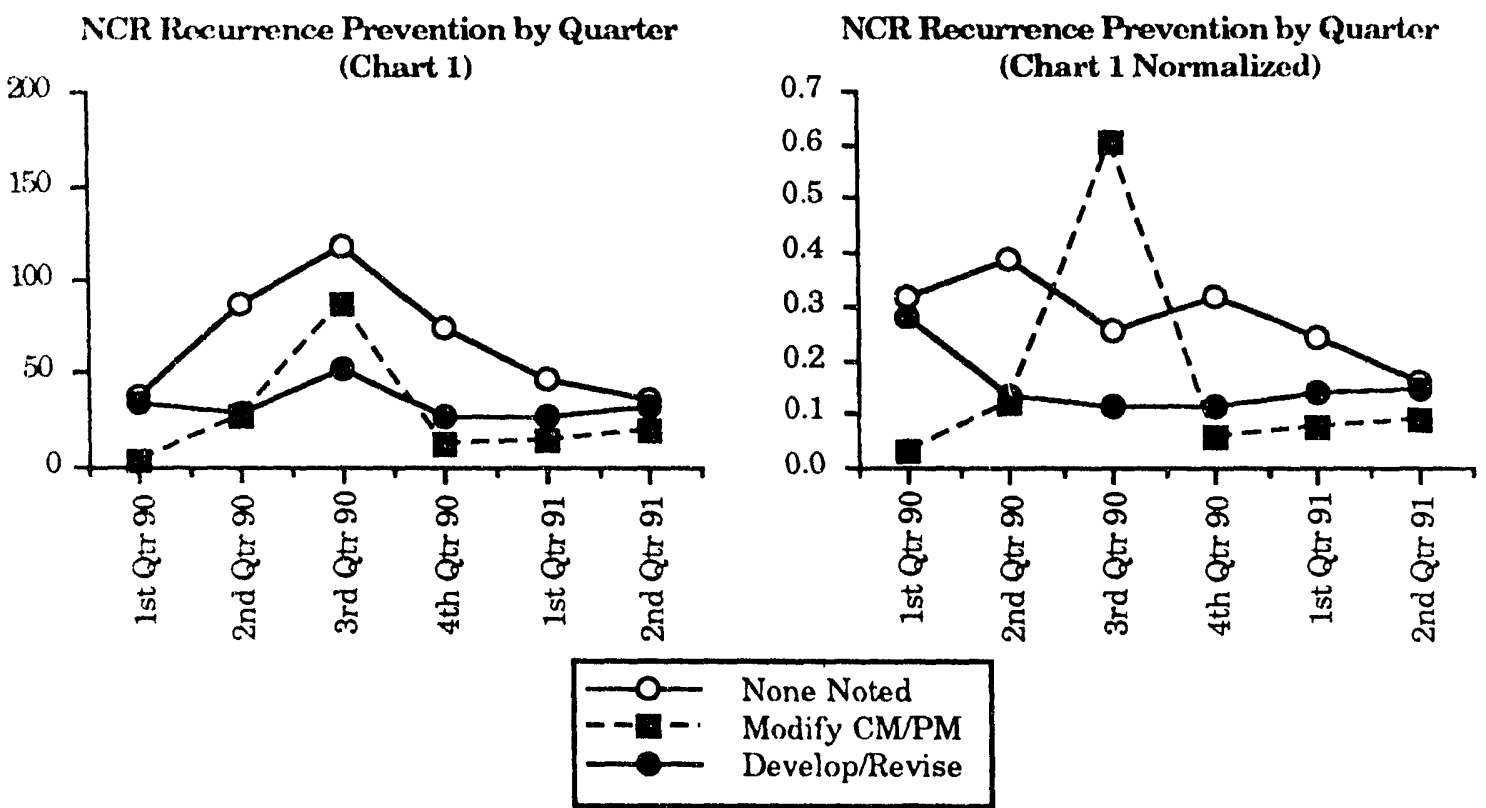

A marked improvement is noted with the reduction in the "None Noted" category. This is a significant step in identifying corrective actions which have a positive impact on recurrence prevention. 


\section{Reactor Restart Division \\ Trend Analysis Report \\ Second Quarter 1991}

(Action To Prevent Recurrence continued)

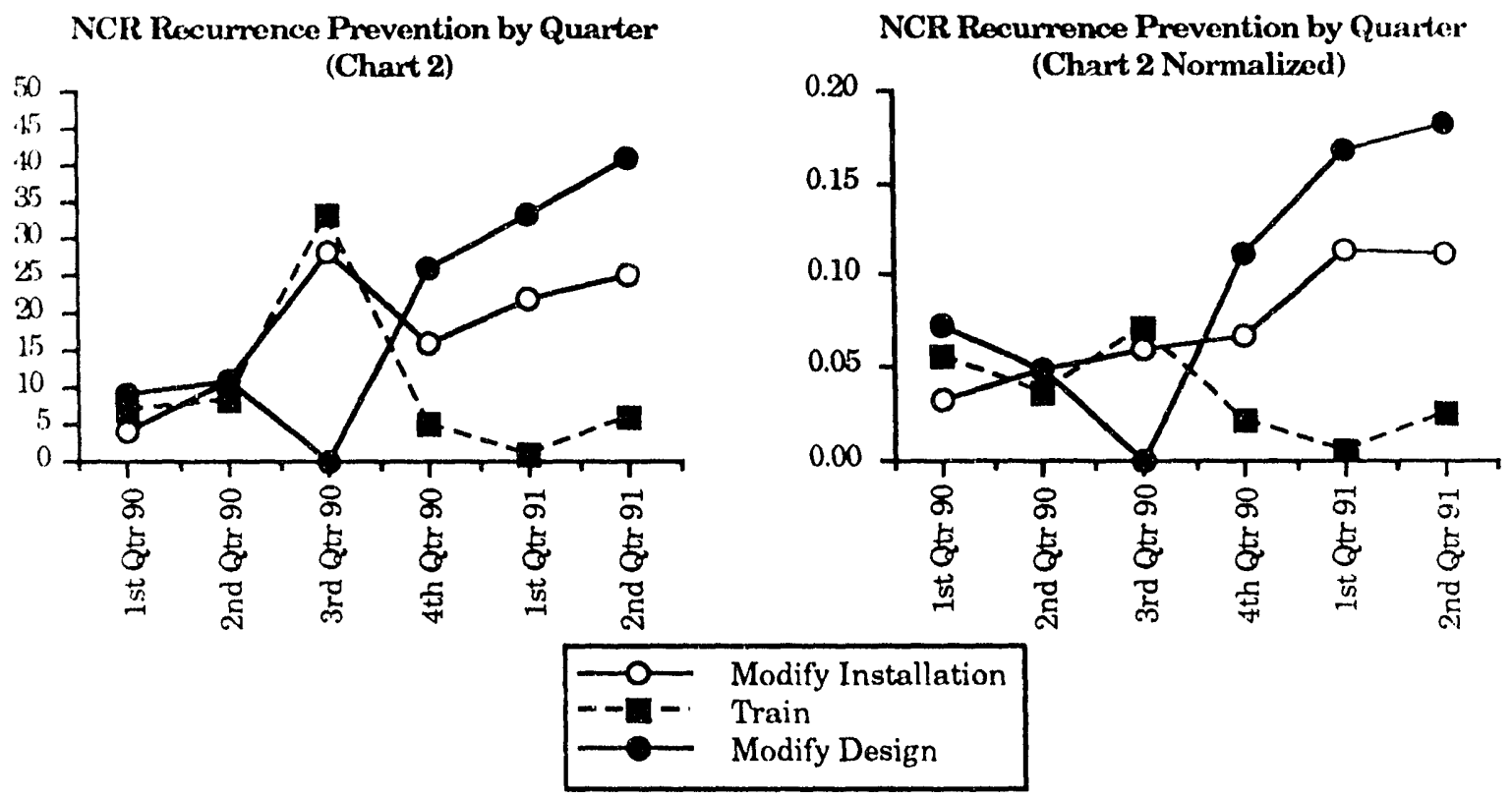

"Modify Design" shows a rise in occurrences due to the number of drawings being revised to show "as built" configurations. The "All Others" category has been dropped from this report. This is due to several new categories being added at the request of Site QA. As a baseline is established using these new categories these charts will be updated in future reports to reflect actual performance. 


\section{Reactor Restart Division \\ Trend Analysis Report \\ Second Quarter 1991}

\section{Surveillance Reports}

The 45 Surveillance findings from 20 Surveillance reports included in this analysis were distributed among the operating areas as follows:

$\begin{array}{lr}\text { K Area } & 19 \\ \text { L Area } & 1 \\ \text { P Area } & 0\end{array}$

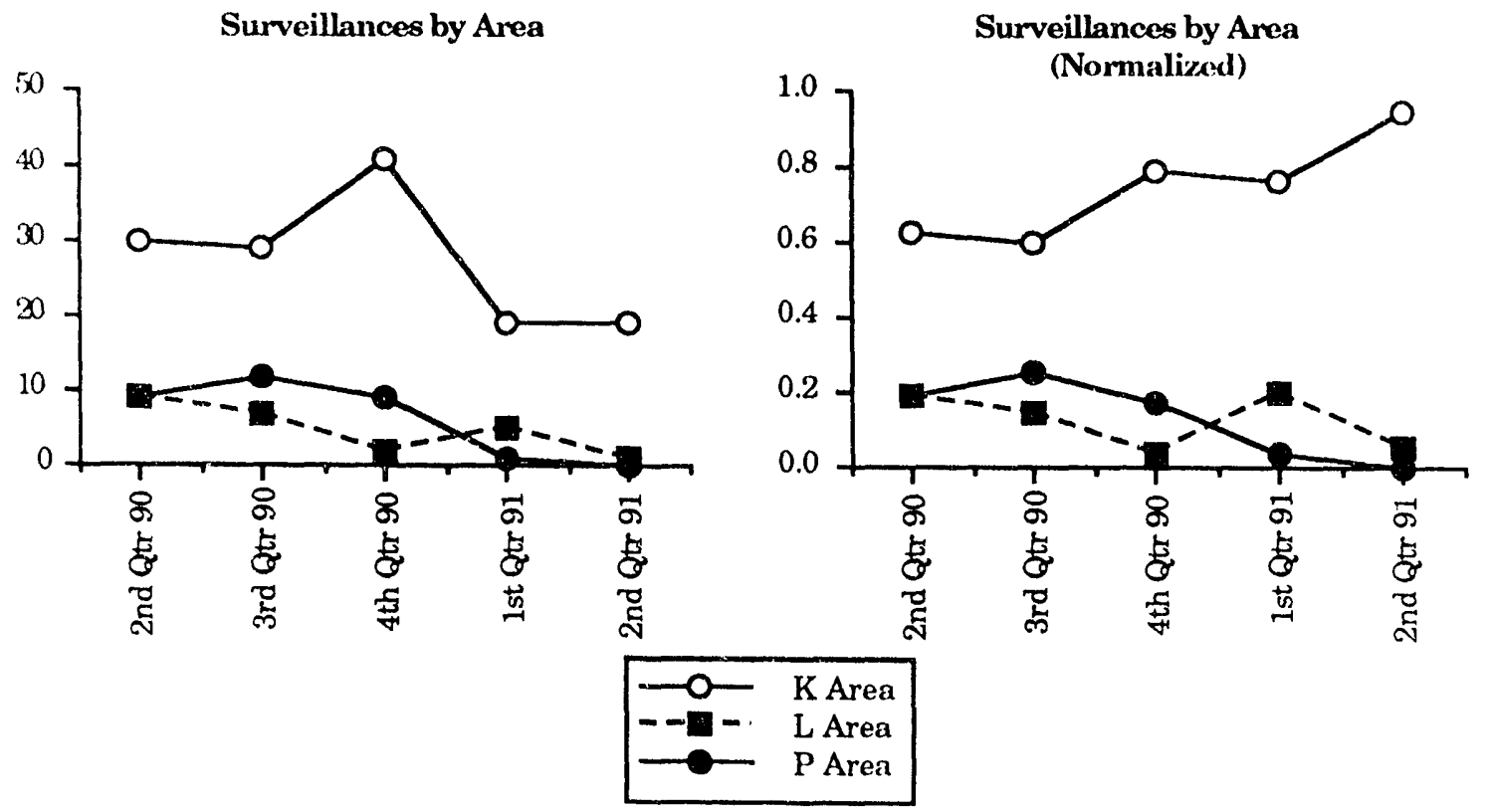

$K$ Area continues to be the focus for surveillance activity due to the emphasis for restart. 


\section{Reactor Restart Division Trend Analysis Report Second Quarter 1991}

The findings identified in the surveillances utilized in this report's analysis were categorized as follows:

Procedure Violation

Satisfactory Observation

Documentation

Job $\mathrm{Pl}_{\mathrm{n}} \mathrm{n}$ Deficiency

Policy/Manual

All Others
26

11

6

2

0

0
Surveillance Findings by Quarter

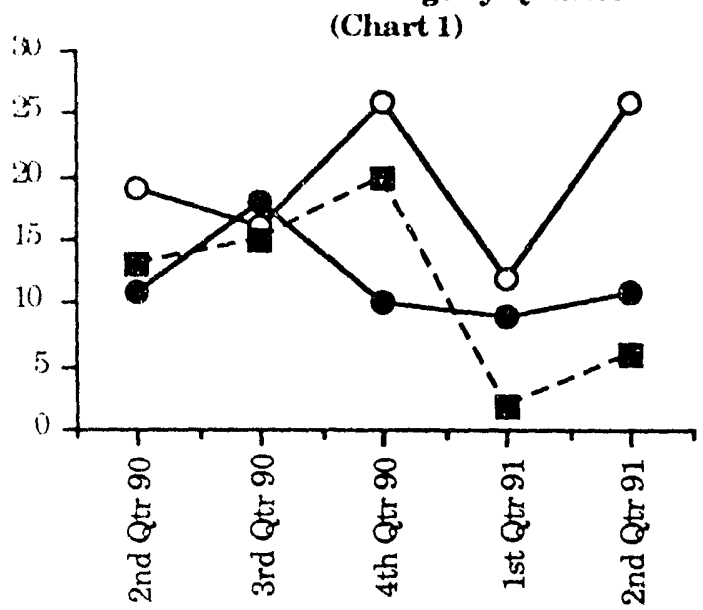

Surveillance Findingss by Quarter (Chart 1 Normalized)

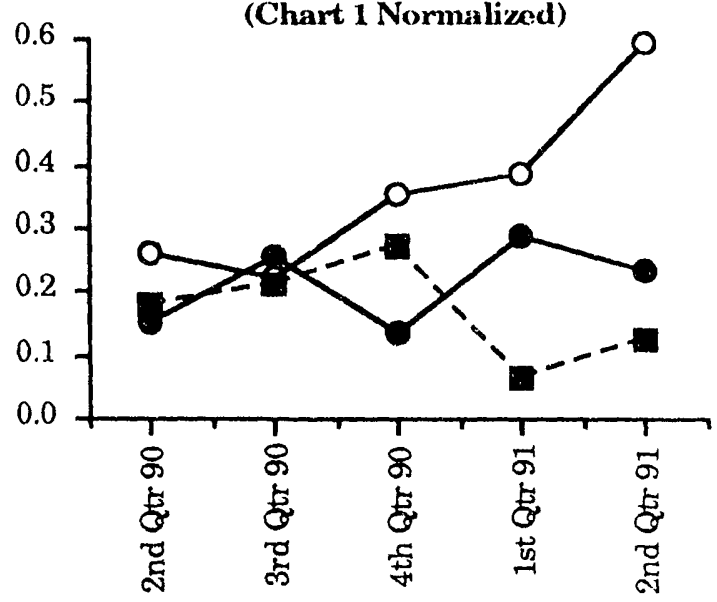

Procedure Violation

- D- Documentation

Satisfactory Observation

The rise in the number of "Procedure Violations" noted in this report is the start of a negative upward trend. The importance of procedural compliance needs to be re-emphasized. A direct correlation with this finding category will be shown in the following section when causal factors will be discussed. 


\section{Reactor Restart Division \\ Trend Analysis Report Second Quarter 1991}

(Surveillance Finding Analysis continued)

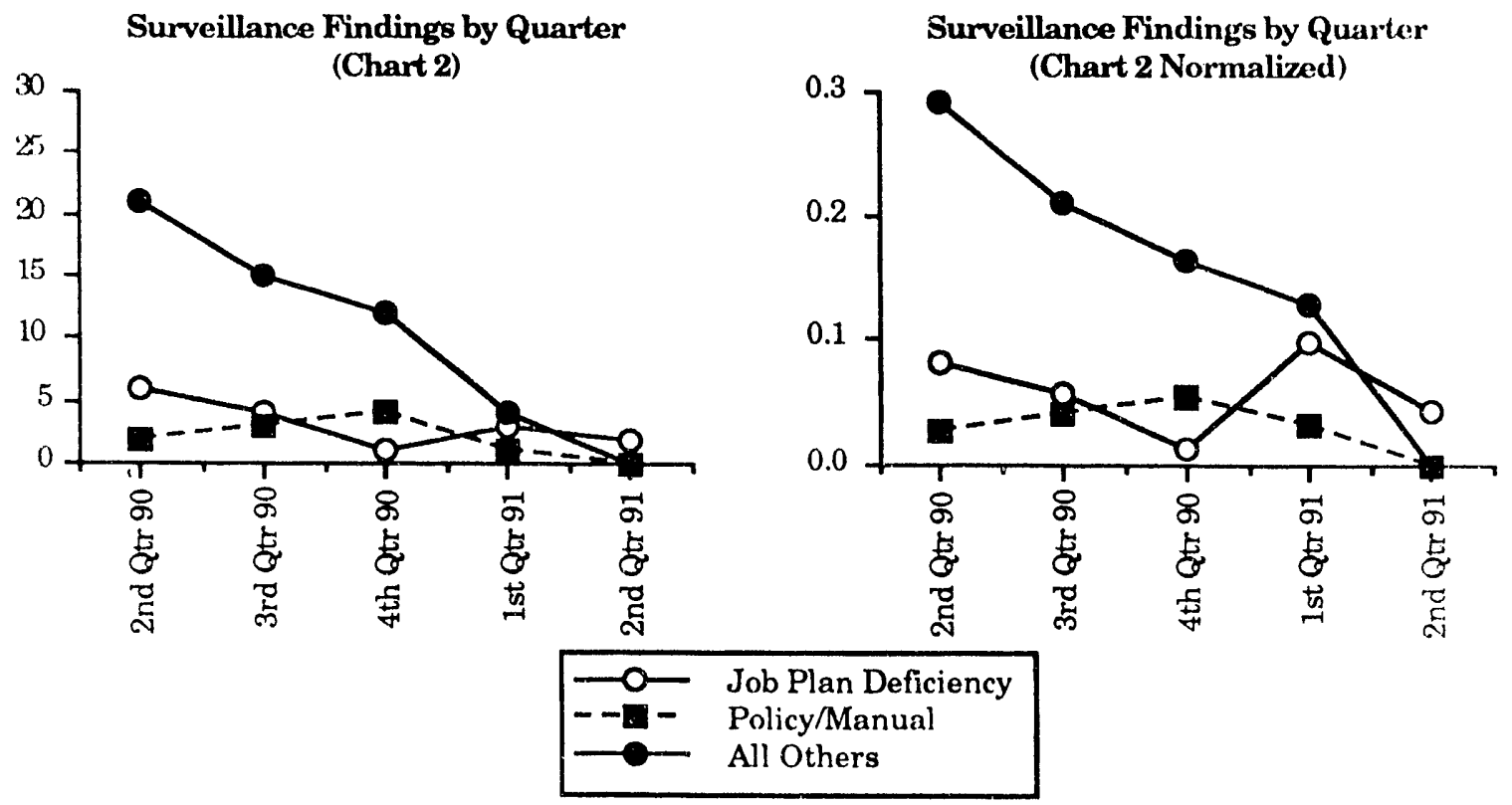

The "All Others" category has been dropped from this report. This is due to several new categories being added at the request of Site QA. As a baseline is established using these new categories these charts will be updated in future reports to reflect actual performance. 


\section{Reactor Restart Division Trend Analysis Report Second Quarter 1991}

The following causes assigned to the Surveillance Reports included in this quarter's analysis:

SPAC LTA

Procedure Followed Incorrectly

Procedure Wrong/Incomplete

Procedure Not Used

All Others
21

5

2

3

3

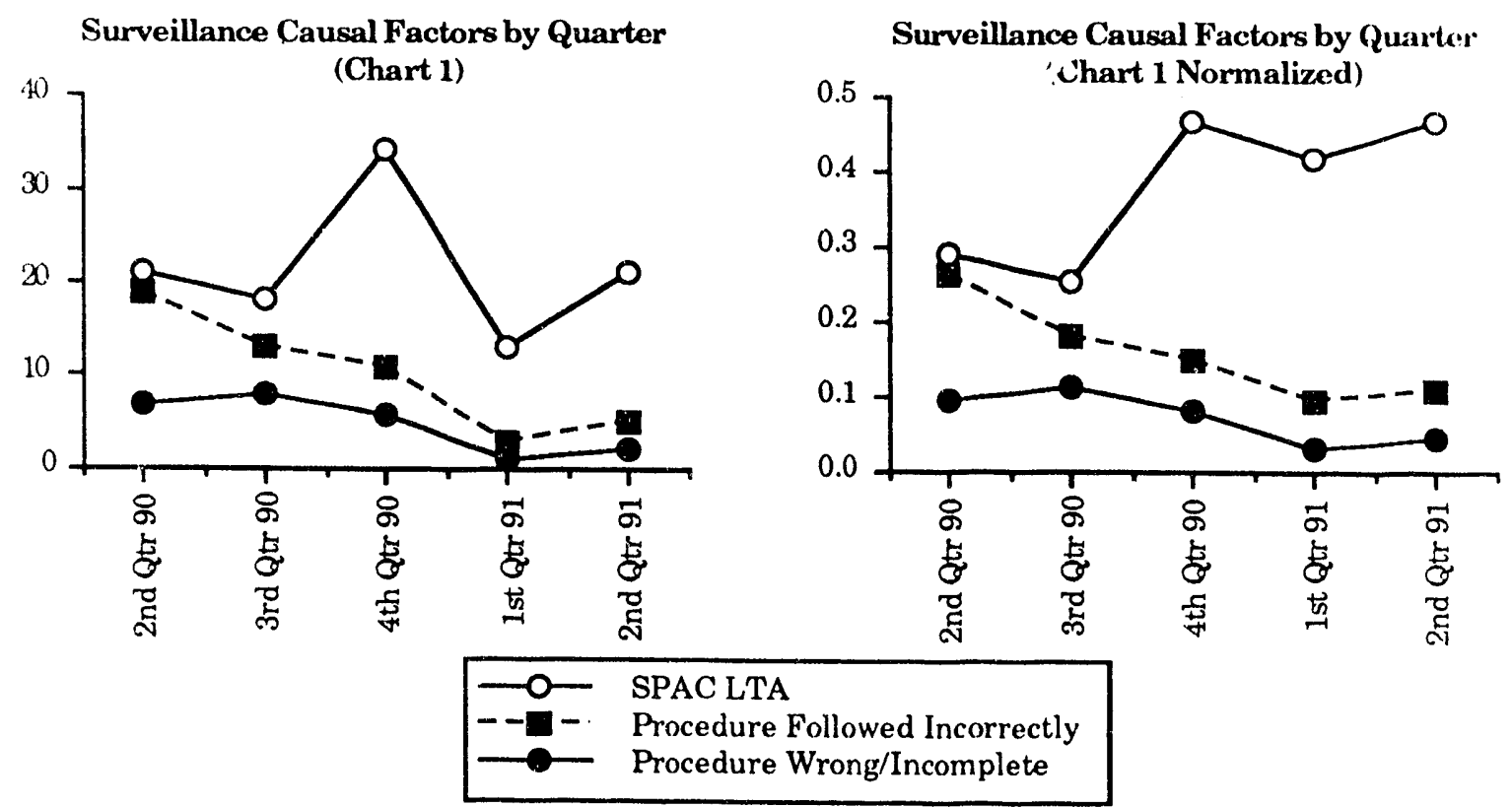

Thirty-one of forty-five identified causal factors identified correlate to "Procedure Violations". This is 69 percent of the data population used in this report's analysis. This information will be directed for management attention and will be analyzed further. This is the beginning of a significant adverse trend. 


\section{Reactor Restart Division Trend Analysis Report Second Quarter 1991}

(Surveillance Report Causal Factor Analysis continued)

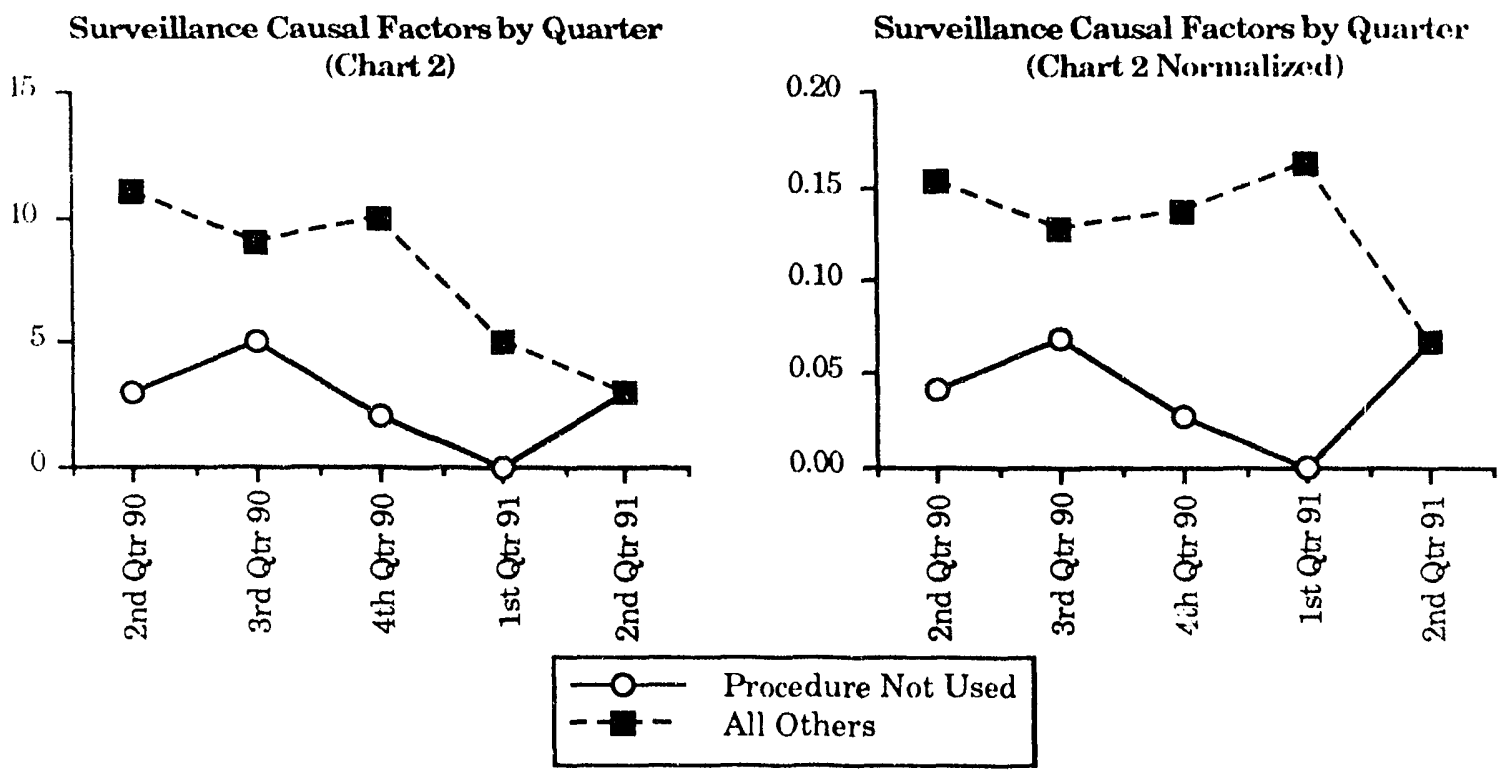




\section{Reactor Restart Division \\ Trend Analysis Report Second Quarter 1991}

Actions taken to prevent recurrence of the deficiencies identified in the surveillance reports are:

Train

Develop/Revise

11

Satisfactory Observation $\quad 11$

All Others

2

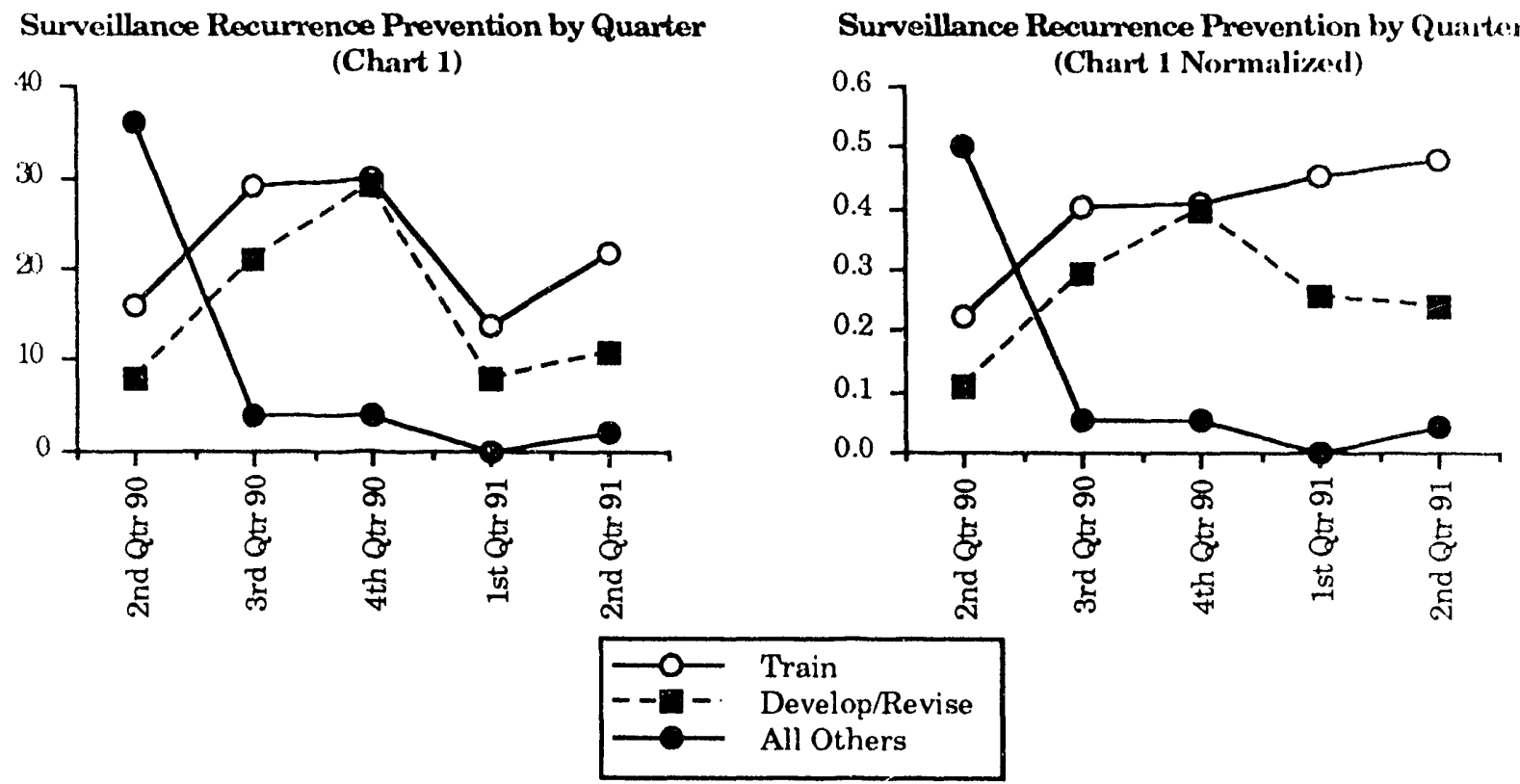

The corrective actions identified from the surveillance reports shows steps are being taken to eliminate recurrence of identified deficiencies. As new and revised procedures come on line it is imperative that timely training is provided and follow up is made to assure personnel understand these procedures. This will establish a solid basis for procedural compliance and avert this condition becoming a significant condition adverse to quality. 


\section{Reactor Restart Division \\ Trend Analysis Report Second Quarter 1991}

\section{Corrective Action Reports}

Five Corrective Action Reports were issued during this report period. This data will be summarized without supporting charts due to the small data population.

All five reports dealt with procedural or administrative control deficiencies. The breakdown is as follows:

$\begin{array}{ll}\text { M\&TE } & 2 \\ \text { NCR Program } & 1 \\ \text { Used Equipment Control } & 1 \\ \text { JTG Review } & 1\end{array}$

In all cases a lack of adequate procedure or administrative policy is cited as the main causal factor. Steps are being taken to develop or revise the control systems needed to prevent recurrence of these conditions. 

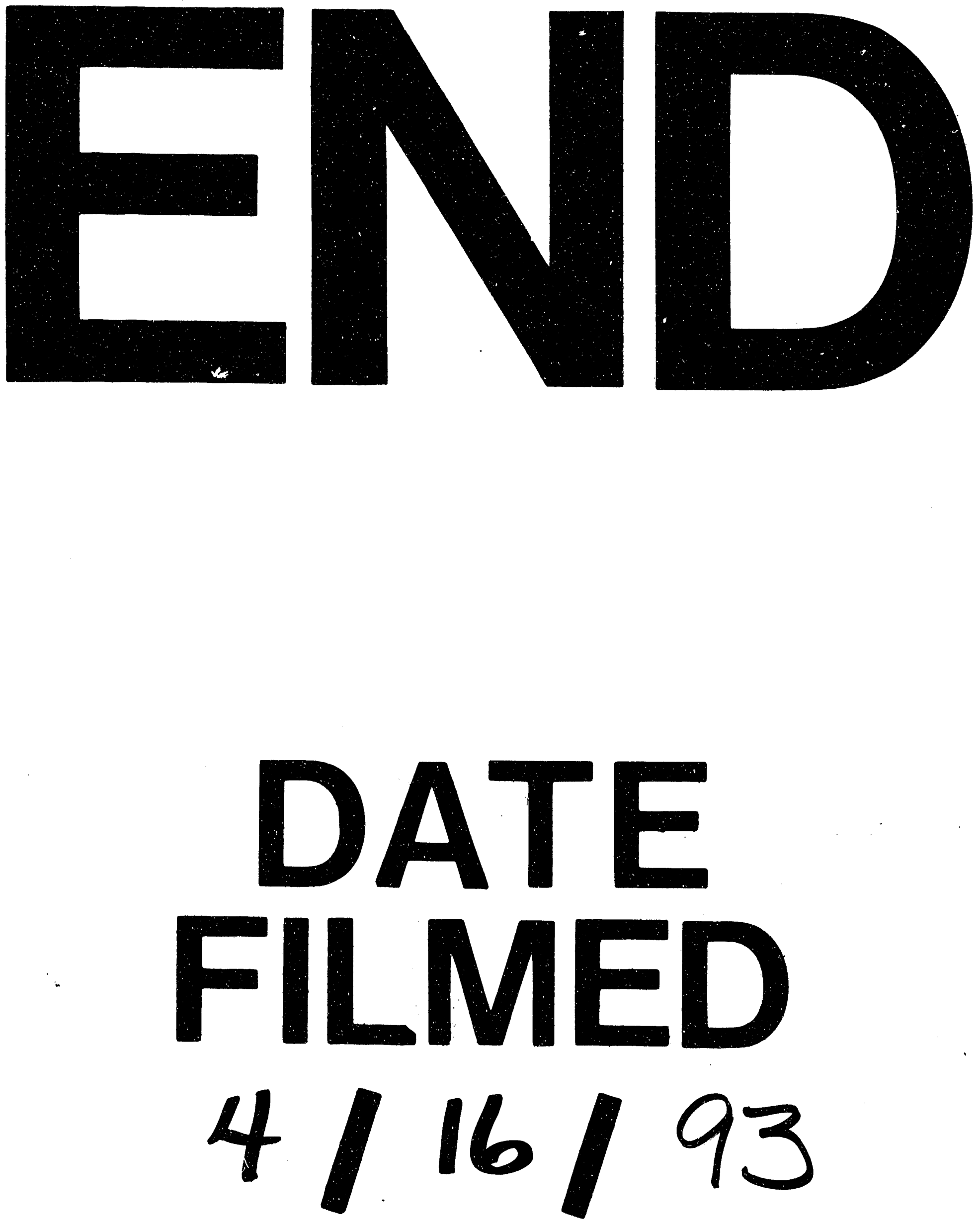

1 
